\title{
Role of Novel Oral Anticoagulants in the Treatment of Antiphospholipid Syndrome
}

\author{
C. Whitney White, PharmD, BCPS",; Angela R. Thomason, PharmD, BCPS*; \\ and Katie Boyd, PharmD, BCPS:s
}

\begin{abstract}
Background: Antiphospholipid syndrome (APS) is an autoimmune disease characterized by thrombosis or pregnancy loss with persistent positive antibodies. Standard treatment for APS with history of thromboembolism is heparin or low-molecular-weight heparin followed by a vitamin $\mathrm{K}$ antagonist (VKA). Novel oral anticoagulants (NOACs) could be effective in patients with APS, but none carry indications for treatment related to APS.

Clinical Evidence: Five case reports or series with rivaroxaban and dabigatran suggest thrombotic events occur most often in the higher risk population (arterial thrombosis and/or triple positive antibodies) or in patients who had recurrent VTEs on warfarin therapy. An observational cohort in 26 APS patients using dabigatran or rivaroxaban described a recurrent thrombotic event in only 1 patient after 8 months of treatment. The event-free survival rate was $87.9 \%$ at 12 months. Three controlled clinical trials are underway to evaluate the thrombotic risk of NOACs (RAPS, TRAPS, and ASTRO-APS).

Discussion: There are no completed studies that evaluate the use of NOACs in APS compared to VKAs. One major disadvantage of the NOACs is the limited availability of reversal agents for patients with a major bleeding episode. An increased risk of thrombotic events is associated with arterial occlusions and triple antibody positivity APS with both warfarin and NOACs; this is currently being researched in the TRAPS study.

Conclusion: Based on current available evidence, VKAs remain the standard of care in the treatment of APS. Results of ongoing trials may offer more guidance on how to appropriately use NOACs for patients with APS.
\end{abstract}

Key Words—antiphospholipid syndrome, novel oral anticoagulants, warfarin

Hosp Pharm 2016;51:759-767

A ntiphospholipid syndrome (APS) is an autoimmune disease characterized by thrombosis or pregnancy loss with persistent positive antibodies. Thrombosis is one of the hallmarks of the syndrome, with venous thromboembolism (VTE) as the most common manifestation. ${ }^{1,2}$ Among patients with acute VTE, approximately $10 \%$ are positive for APS. ${ }^{3}$ Other common manifestations of APS are renal thrombotic microangiopathy, transient ischemic attack, stroke, myocardial infarction, cardiac valvular disease, cognitive impairment, thrombocytopenia, and hemolytic anemia. ${ }^{1,2,4}$ Of the autoantibodies associated with APS, lupus anticoagulant is the strongest predictor of thrombotic complications related to the disorder. ${ }^{2,4,5}$

Diagnosis of APS is confirmed by having a documented clinical episode (vascular thrombosis or pregnancy morbidity) and at least one positive antibody laboratory test. The antibody laboratory test must be positive on 2 or more occasions, at least 12 weeks apart. ${ }^{4,6}$ Plasma antibodies associated with APS are lupus anticoagulant, anticardiolipin, and anti-beta

\footnotetext{
"Associate Professor of Pharmacy Practice, McWhorter School of Pharmacy, Samford University, Birmingham, Alabama; ${ }^{\dagger}$ Clini-

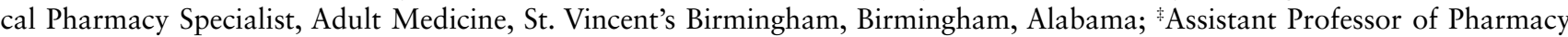
Practice, McWhorter School of Pharmacy, Samford University, Birmingham, Alabama; ${ }^{\S}$ Clinical Pharmacy Specialist, Baptist Health Center Primary Care, Birmingham, Alabama. Corresponding author: Angela R. Thomason, PharmD, BCPS, Department of Pharmacy Practice, 800 Lakeshore Drive, Birmingham, AL 35229-7027; phone: 205-726-4476; fax: 205-726-2669; e-mail: adrobert@samford.edu
} 
2-glycoprotein I. Coagulation assays are used to identify lupus anticoagulant antibodies, because they are associated with a prolonged clotting time. In contrast, immunoassays are used to measure immunologic reactivity to phospholipids to determine the presence of anticardiolipin and anti-beta2-glycoprotein I antibodies. ${ }^{7,8}$ Guidelines for detection of lupus anticoagulant stress the importance of proper patient selection for testing in order to avoid false-positive results. ${ }^{9}$ Testing for lupus anticoagulant in asymptomatic patients is highly discouraged. ${ }^{10}$

In patients with recurrence of VTE on anticoagulation therapy with either a novel oral anticoagulant (NOAC) or vitamin K antagonist (VKA), the 2016 guidelines from the American College of Chest Physicians recommend 1 month of low-molecular-weight heparin along with an evaluation for adherence and malignancy. However, the guidelines note that this recommendation is based on low-quality evidence and assessment of probable cause of reoccurrence. After a 1-month period, patients should restart their oral anticoagulation therapy unless cancer was identified. In addition, the guidelines recommend choosing anticoagulation therapy based on patient-specific factors such as renal or liver disease, coronary artery disease, adherence, and patient preference. The 2016 guidelines mention APS as a risk factor associated with recurrent VTE, although specific treatment is not outlined. ${ }^{11}$ Prior to the new guidelines, the standard treatment for APS with history of thromboembolism was long-term therapy with a VKA such as warfarin to target an international normalized ratio (INR) of 2.5 (range, 2.0-3.0). ${ }^{12}$ In APS patients who have had recurrent thromboembolic events and arterial thrombosis, a target INR of $3.0(2.5-3.5)$ was suggested. ${ }^{5}$ However, this is controversial. Two studies have shown high-intensity warfarin therapy (INR 3.14.0) was not superior to moderate-intensity warfarin therapy (INR 2-3) in the prevention of thrombosis in patients with APS. ${ }^{13,14}$ Therefore, moderate-intensity warfarin (INR 2-3) therapy is preferred for patients with APS compared to high-intensity warfarin in the prevention of recurrent thrombosis. ${ }^{12}$

Treatment of APS with a VKA presents a challenge in monitoring and adjustment, and it can be complicated by lupus anticoagulant interference on INR results. Lupus anticoagulant interference can lead to variability and misinterpretation of the INR, which can result in under-dosing of the VKA and VTE recurrence. ${ }^{15,11}$ VKAs also have several drugdrug and drug-food interactions that require dietary restrictions and frequent laboratory monitoring to achieve a therapeutic INR. ${ }^{5}$ Despite treatment with VKAs, thrombosis still occurs in $5 \%$ to $20 \%$ of APS patients; therefore, complete protection against all future thrombotic events is highly improbable in some APS patients. ${ }^{13,16}$

Several new APS treatment approaches are emerging, including combination antiplatelet therapies (low-dose aspirin plus clopidogrel or dipyridamole), oral anti-factor Xa medications (rivaroxaban, apixaban), direct thrombin inhibitors (dabigatran), statins (fluvastatin, rosuvastatin), hydroxychloroquine, and B-cell depletion therapy (rituximab). ${ }^{16}$ In theory, the NOACs should be effective in patients with APS. Several NOACs (rivaroxaban, dabigatran, edoxaban, and apixaban) are on the market, but none carry indications for treatment related to APS or other hypercoagulable disorders. The NOACs are more attractive because of the need for less routine laboratory monitoring, fewer diet restrictions, decreased drug interactions, and a once- to twicedaily dosing strategy. In addition, they have predictable anticoagulant effects, yet these agents are at a disadvantage because of limited reversal possibilities and the possibility of patient-specific dosage adjustments. ${ }^{5,15}$ An overview of the NOACs is outlined in Table $1 .{ }^{17-22}$ Currently, dabigatran, rivaroxaban, and apixaban have published literature related to treatment in APS and are the focus of this article.

\section{CLINICAL EVIDENCE \\ Case Studies}

Several case reports have been published regarding the use of NOACs in APS (Table 2). Five of the case reports reference rivaroxaban, whereas 2 include patients on dabigatran. Signorelli et al reported 8 patients (mean age of 36 years and $62.5 \%$ female) who suffered a thrombotic event while on NOAC therapy. Of those 8 patients, 3 had a thrombotic event on warfarin therapy prior to switching to rivaroxaban, and 5 had a reported target INR range of 3 to 4 . In addition, one patient was identified as nonadherent to medication regimens including warfarin and rivaroxaban. ${ }^{23}$ Win and Rodgers reported 3 patients with a thrombotic event on NOAC therapy within 6 to 12 months after switching from warfarin therapy. All these patients had either failed warfarin therapy or had difficulty maintaining a therapeutic INR due to nonadherence or genetic predisposition related to cytochrome P450 (CYP) 2C9. Two patients were switched to rivaroxaban, and one patient received a reduced dose of dabigatran (150 mg daily). All 3 patients reported a thrombotic event while receiving 
Table 1. Summary of the characteristics of the novel oral anticoagulants ${ }^{17-22}$

\begin{tabular}{|c|c|c|c|c|c|}
\hline Drug & Rivaroxaban & Apixaban & Edoxaban & Betrixaban & Dabigatran \\
\hline Target & Factor Xa & Factor Xa & Factor Xa & Factor Xa & Thrombin \\
\hline Bioavailability & $>80 \%$ & $50 \%$ & $62 \%$ & $34 \%$ & $3-7 \%$ \\
\hline Protein binding & $92 \%-95 \%$ & $87 \%$ & $55 \%$ & $60 \%$ & $35 \%$ \\
\hline Half-life $^{\mathrm{a}}$ & 9 hours & 12 hours & 10-14 hours & 20 hours & 12-17 hours \\
\hline $\begin{array}{l}\text { Deep vein } \\
\text { thrombosis dose } \\
\text { and frequency }\end{array}$ & $20 \mathrm{mg}$ once daily & $\begin{array}{l}5 \text { mg twice daily } \\
\text { (may reduce to } 2.5 \\
\text { mg after } 6 \text { months of } \\
\text { therapy) }\end{array}$ & $60 \mathrm{mg}$ once daily & $\begin{array}{l}80 \mathrm{mg} \text { once } \\
\text { daily }^{\mathrm{b}}\end{array}$ & $150 \mathrm{mg}$ twice daily \\
\hline $\begin{array}{l}\text { Dose to be } \\
\text { taken with food }\end{array}$ & Yes & $\begin{array}{l}\text { May be taken } \\
\text { without regard for } \\
\text { food. }\end{array}$ & $\begin{array}{l}\text { May be taken } \\
\text { without regard for } \\
\text { food. }\end{array}$ & $\begin{array}{l}\text { No } \\
\text { (fatty food } \\
\text { reduces } \\
\text { bioavailability } \\
\text { by } 50 \% \text { ) } \\
\end{array}$ & $\begin{array}{l}\text { No } \\
\text { (food delays time } \\
\text { to peak by } 2 \\
\text { hours) }\end{array}$ \\
\hline $\begin{array}{l}\text { Drug } \\
\text { interactions }\end{array}$ & $\begin{array}{l}\text { CYP3A4 inhibitors, } \\
\text { P-gp inhibitors }\end{array}$ & $\begin{array}{l}\text { CYP3A4 inhibitors, } \\
\text { P-gp inhibitors }\end{array}$ & $\begin{array}{l}\text { CYP3A4 inhibitors, } \\
\text { and P-gp inhibitors }\end{array}$ & NR & $\begin{array}{l}\text { Proton pump } \\
\text { inhibitors, } \\
\text { antacids, } \\
\text { dronedarone, P-gp } \\
\text { inhibitors }\end{array}$ \\
\hline $\begin{array}{l}\text { Renal } \\
\text { elimination }\end{array}$ & $66 \%$ renal & $27 \%$ & $50 \%$ & $5 \%-7 \%$ & $80 \%$ \\
\hline $\begin{array}{l}\text { Renal dosing } \\
\text { adjustments }^{\mathrm{c}}\end{array}$ & $\begin{array}{l}\mathrm{CrCL}<30 \mathrm{~mL} / \mathrm{min}: \\
\text { avoid use }\end{array}$ & $\begin{array}{l}\text { Patients with serum } \\
\text { creatinine }>2.5 \mathrm{mg} / \\
\mathrm{dL} \text { or } \mathrm{CrCL}<25 \mathrm{~mL} / \\
\text { min were excluded } \\
\text { in trials. }\end{array}$ & $\begin{array}{l}\text { CrCL }<15 \text { to } 50 \\
\mathrm{~mL} / \mathrm{min}: 30 \mathrm{mg} \\
\text { once daily } \\
\text { CrCL }<15 \mathrm{~mL} / \mathrm{min}: \\
\text { not recommended }\end{array}$ & NR & $\begin{array}{l}\text { Contraindicated in } \\
\text { CrCL } \leq 30 \mathrm{~mL} / \mathrm{min}\end{array}$ \\
\hline $\begin{array}{l}\text { Hepatic dosing } \\
\text { adjustments }\end{array}$ & $\begin{array}{l}\text { Contraindicated in } \\
\text { Child-Pugh class B } \\
\text { and C }\end{array}$ & $\begin{array}{l}\text { Child-Pugh class C: } \\
\text { Not recommended }\end{array}$ & $\begin{array}{l}\text { Child-Pugh class } \\
\text { B and C: Not } \\
\text { recommended }\end{array}$ & NR & $\begin{array}{l}\text { Child-Pugh } \\
\text { Class C/severe } \\
\text { impairment: Not } \\
\text { recommended }\end{array}$ \\
\hline $\begin{array}{l}\text { Additional } \\
\text { comments }\end{array}$ & $\begin{array}{l}\text { Note: } \mathrm{CrCl} 15 \text { to } \\
50 \mathrm{~mL} / \mathrm{min}: 15 \mathrm{mg} \\
\text { once daily with the } \\
\text { evening meal in } \\
\text { nonvalvular atrial } \\
\text { fibrillation. Dose } \\
\text { reduction in patients } \\
\text { with moderate to } \\
\text { severe chronic kidney } \\
\text { disease may be } \\
\text { considered, although } \\
\text { safety and efficacy of } \\
\text { this approach has not } \\
\text { been established. }\end{array}$ & $\begin{array}{l}\text { Note: if a patient is } \\
\geq 80 \text { years of age and } \\
\text { either weighs } \leq 60 \\
\text { kg or has a serum } \\
\text { creatinine } \geq 1.5 \mathrm{mg} / \\
\text { dL, then reduce dose } \\
\text { to } 2.5 \mathrm{mg} \text { twice } \\
\text { daily. }\end{array}$ & $\begin{array}{l}\text { Reduced efficacy in } \\
\text { nonvalvular atrial } \\
\text { fibrillation patients } \\
\text { with } \mathrm{CrCl}>95 \mathrm{~mL} / \\
\text { min. } \\
\text { Should not be used } \\
\text { in patients with } \\
\mathrm{CrCl}>95 \mathrm{~mL} / \mathrm{min} \text {. }\end{array}$ & $\begin{array}{l}\text { Currently in } \\
\text { phase } 3 \text { studies. } \\
\text { Potential } \\
\text { reversal agent: } \\
\text { andexanet alfa } \\
\text { by the same } \\
\text { company. }\end{array}$ & $\begin{array}{l}\text { Do not break, } \\
\text { chew, or open } \\
\text { capsules (increased } \\
\text { absorption by } \\
75 \%) .\end{array}$ \\
\hline
\end{tabular}

\footnotetext{
Note: $\mathrm{CrCl}=$ creatinine clearance; $\mathrm{CYP}=$ cytochrome $\mathrm{P} 450 ; \mathrm{NR}=$ not reported; P-gp = P-glycoprotein.

${ }^{a}$ Under normal renal clearance.

${ }^{\mathrm{b}}$ Dose based on the phase 3 clinical trial currently in progress. Currently being studied as a twice-daily dose in venous thromboembolism (VTE) prevention in total knee replacement.

${ }^{c}$ Based on Cockcroft-Gault formula for renal clearance.
} 


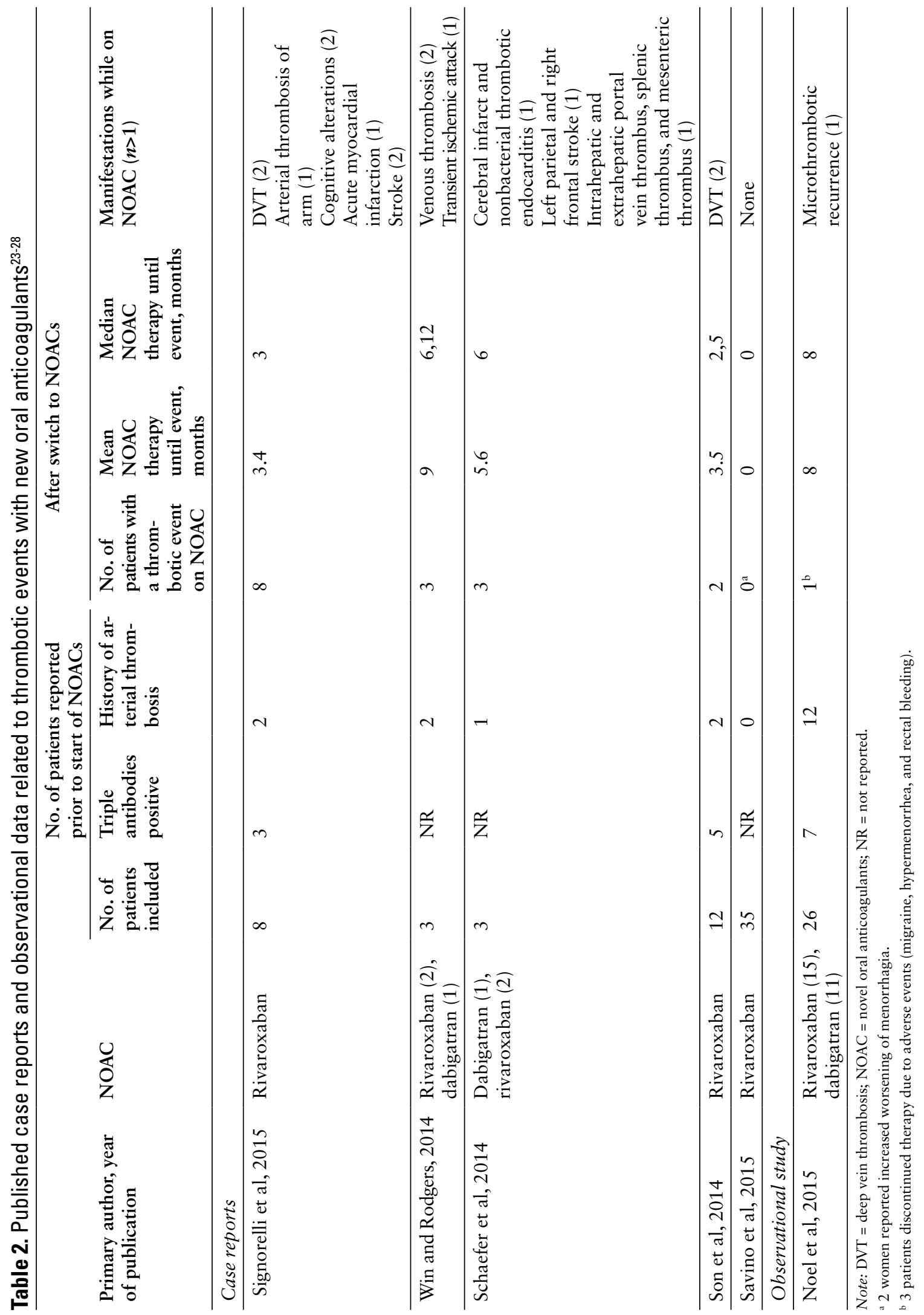


NOAC therapy. All patients improved after switching to either enoxaparin $(n=2)$ or fondaparinux $(n=1) \cdot{ }^{24}$ Schaefer et al described 3 patients who experienced a thrombotic event while on NOAC. Two patients reported bleeding complications with warfarin, one of whom had a target INR of 3 to 4 prior to switching to a NOAC. The third patient switched to rivaroxaban due to patient preference related to frequent INR monitoring with warfarin. One patient was switched to lower dabigatran dose (150 mg once daily) based on moderate renal impairment, and others were dosed with rivaroxaban $20 \mathrm{mg}$ daily due to patient preference. All patients experienced another thrombotic event on an NOAC. Two patients were transitioned to warfarin and one to enoxaparin. ${ }^{25}$

Son et al followed 12 patients at one institution who were switched from a VKA to rivaroxaban due to logistical issues with the patients' professional activities in conjunction with frequent laboratory monitoring or unstable INR values. Patients ranged from 22 to 52 years of age, and $58 \%$ were female. Patients with a history of stroke and/or multiple risk factors for thrombotic events also received low-dose aspirin. Of the 12 patients, only 2 experienced a thrombotic event on rivaroxaban over a treatment range of 10 to 16 months. One patient had a deep vein thrombosis (DVT) during an exacerbation of systemic lupus erythematosus (SLE), and the other developed a DVT after a minor lower limb injury. Both of these patients had a coexisting SLE and triple positivity profile. ${ }^{26}$

Savino et al tracked 35 patients who were either started on rivaroxaban prior to the clinical trial of rivaroxaban in APS (RAPS) or failed to qualify for the enrollment in the trial. Patients were excluded if they had arterial thrombosis. The patients ranged from 17 to 75 years of age, and the majority were female (24 woman; 11 men). The patients either had a previous DVT, pulmonary embolism (PE), or both. All were previously treated with warfarin with a target INR of 2 to 3. Patients were followed for a median of 10 months (6-24 months) and were treated with rivaroxaban of $20 \mathrm{mg}$ once daily. During that time frame, no patient suffered a recurrent thrombotic event. Two patients reported increased menorrhagia. ${ }^{27}$

\section{Observational Cohort Study}

Noel et al conducted a multicenter observational study that followed 26 APS patients treated with either dabigatran $(n=11 ; 150 \mathrm{mg}$ twice daily) or rivaroxaban ( $n=13 ; 20 \mathrm{mg}$ once daily). Two patients received a different dose of rivaroxaban $(n=1,15 \mathrm{mg}$ twice daily; $n=1,15 \mathrm{mg}$ daily). Twelve patients had primary APS, 9 had APS associated with SLE, and 5 had APS associated with various other syndromes. Twenty-two patients had normal renal function, and 4 patients had moderate kidney impairment (glomerular filtration rate $40-60 \mathrm{~mL} / \mathrm{min} / 1.73 \mathrm{~m}^{2}$ ). Twenty patients had previous anticoagulation therapy (warfarin, $n=19$; fondaparinux, $n=1$ ). Two patients were switched from warfarin therapy: one patient had a recurrent venous thrombosis and the other had a bleeding event. Sixteen patients were switched to the NOAC due to labile INRs. One patient experienced a recurrent thrombotic event after 8 months of rivaroxaban. The event-free survival rate was $87.9 \%$ at 12 months and $82.4 \%$ at 24 months. Three patients withdrew from the rivaroxaban group due to adverse events ( $n=2$, bleeding events; $n=1$, recurrent migraines). ${ }^{28}$

\section{Controlled, Clinical Trials}

Three controlled, clinical trials are currently underway that evaluate NOACs compared to warfarin with an adjusted INR of 2 to 3 (target 2.5) in APS. An overview of the studies is outlined in Table 3.

Rivaroxaban in antiphospholipid syndrome (RAPS) clinical trial is designed to evaluate the level of anticoagulation compared to warfarin in the APS population with or without SLE and a history of VTE. The secondary endpoints focus more on efficacy and safety. Patients with arterial thrombosis, severe renal impairment, history of nonadherence, or a thrombotic event while on warfarin with a therapeutic INR (2-3) were excluded from the trial. ${ }^{29}$

The Trial on Rivaroxaban in Thrombotic Antiphospholipid Syndrome (TRAPS) is designed to determine noninferiority of rivaroxaban compared to warfarin in the prevention of acute thrombosis in patients with triple antiphospholipid antibody positive APS and bleeding risk. Currently in the recruitment phase, this multicenter trial will include patients with arterial thrombosis and moderate renal impairment (creatinine clearance [CrCL] 30-50 mL/min). The moderate renal impairment group will be dosed with rivaroxaban $15 \mathrm{mg}$ once daily based on the recommendation by the American College of Cardiology/American Heart Association Task Force related to dosing in the trials associated with nonvalvular atrial fibrillation. ${ }^{22,30}$

A feasibility pilot study is currently in progress with Apixaban for Secondary Prevention of Thrombosis among Patients with APS (ASTRO-APS). Patients will be enrolled from 2 health care systems comprising more than 160 outpatient clinics and 


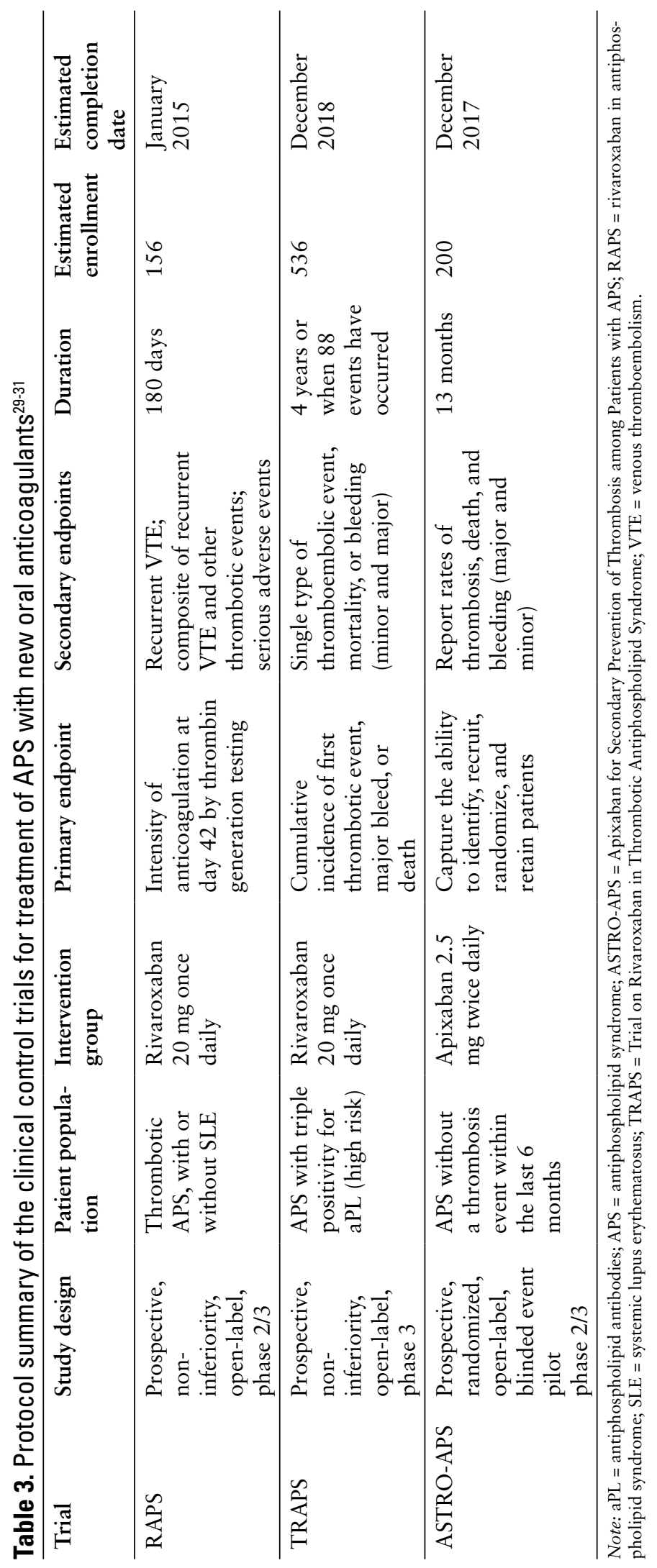


22 hospitals within the United States. The primary aim of the study is to determine recruitment, retention, and enrollment within the APS population. Secondary outcomes are related to the reporting of the efficacy (rates of thrombosis) and safety (bleeding) of apixaban. Exclusion criteria include severe renal impairment $(\mathrm{CrCL}<25 \mathrm{~mL} / \mathrm{min})$, concomitant dual antiplatelet therapy, thrombosis while receiving warfarin with a therapeutic INR (2-3), or the need for a higher target INR (3-4). ${ }^{31}$

\section{DISCUSSION}

The use of NOACs in the treatment of APS remains controversial, yet new data from emerging clinical trials may shed light on the utility of these new agents compared to the current standard of care with warfarin. There are no completed studies that evaluate the use of NOACs compared to VKAs in APS, yet approximately $10 \%$ of patients with acute VTE have APS. Some patients with APS were likely included in previous clinical trials with the NOACs. ${ }^{32,33}$ A small subset of patients with thrombophilic disorders $(5 \%-7 \%)$ was included in the EINSTEIN and EINSTEIN-PE trials with rivaroxaban, but no specific information was recorded to identify the type of hypercoagulable disorder. ${ }^{34,35}$ In the case reports discussed above, thrombotic events seemed to occur most often in the higher risk population or in patients who had previously failed warfarin therapy. The studies by Son, Savino, and Noel, which demonstrated low event rates, included patients reflective of the general APS population. ${ }^{26-28}$ Methodology of the TRAPS clinical trial will target a higher risk population and should therefore provide more meaningful guidance on appropriate therapy across the APS spectrum. ${ }^{30}$

The literature shows that there is an increased risk of thrombotic events associated with a history of arterial occlusions and/or triple antibody positivity APS regardless of treatment with warfarin or the NOACs. In previous trials related to DVT and atrial fibrillation, NOACs were compared to warfarin with a target INR 2 to 3 . With arterial thrombosis, it is controversial whether a higher target INR range of 3 to 4 is beneficial in reducing the risk of thrombotic events in APS, yet the INR target is set at 2.5 in all 3 ongoing trials evaluating use of NOACs in APS. Therefore, equivalent dosing of NOACs for an adjusted INR of 3 to 4 is unknown. Patients with a history of arterial thrombosis and APS may be underdosed with current dosing guidelines. However, APS patients with previous DVT or PE event remained event-free for a median of 10 months while being treated with an NOAC. ${ }^{27}$ This is promising data, which hopefully will be confirmed with new controlled clinical trials.

When evaluating patients for APS, it is important to consider the impact of the anticoagulant on accuracy of diagnostic laboratory assays. Warfarin and heparin products have the potential to affect the results of many of the hypercoagulable panels. Thrombophilia testing is also vulnerable to interference by the NOACs. When the NOACs are given prior to testing, prolonged clotting times can cause false-positive results for protein $C \& S$ and for lupus anticoagulant in assays done with activated partial thromboplastin time (aPTT) and dilute Russell's viper venom time (dRVTT). ${ }^{36}$ However, taipan/ecarin time is less affected by the presence of rivaroxaban and may provide the best specificity and positive predictive value in testing for APS while using rivaroxaban. ${ }^{23,27}$ NOACs can also affect whole blood clotting tests (eg, dabigatran prolongs activated clotting time). ${ }^{37}$ Therefore, testing prior to the administration of anticoagulants or at least 4 to 6 weeks after discontinuation of therapy is recommended. ${ }^{38}$

One major disadvantage of the NOACs is the limited availability of reversal agents for patients with a major bleeding event. ${ }^{4,5}$ In the case and observational studies, minor bleeding was reported with NOACs that required discontinuation of therapy. ${ }^{27.28}$ Currently, Praxbind (idaricizumab; Boehringer Ingelheim) is available for reversal of dabigatran, but no antidotes are available at this time for the oral Factor $\mathrm{Xa}$ inhibitors. Management of bleeding when using the NOACs includes supportive care with blood products and fluids as needed; use of gastric lavage, activated charcoal, or hemodialysis with dabigatran; or possibly use of activated prothrombin complex concentrate (FEIBA NF). ${ }^{39}$

The 14th International Congress of Antiphospholipid Antibodies Task Force published a report on the current treatment trends related to APS in 2014, which recommended VKAs as the treatment option for APS patients with thrombotic events. ${ }^{16}$ However, NOACs may be considered in patients with thrombotic events on subtherapeutic anticoagulation or intolerance to VKAs. ${ }^{16}$ These recommendations were published prior to the availability of the clinical evidence presented in this article. Therefore, the clinical evidence sheds light on the possibility of NOACs for the general APS population. Emerging data from new clinical trials will need to be analyzed to formulate a more contemporary recommendation. 


\section{CONCLUSION}

Based on current available evidence, VKAs remain the standard of care in the long-term treatment of APS. At this time, there is insufficient data to support the use of NOACs in APS patients with recurrent VTE on therapeutic anticoagulation or in APS patients with arterial thrombosis. Results of ongoing trials may offer more guidance on how to appropriately use NOACs for patients with APS.

\section{ACKNOWLEDGMENTS}

The authors report no conflicts of interest.

\section{REFERENCES}

1. Cervera R, Piette JC, Font J, et al. Antiphospholipid syndrome: Clinical and immunologic manifestations and patterns of disease expression in a cohort of 1,000 patients. Arthritis Rheum. 2002;46:1019-1027.

2. Chighizola CB, Andreoli L, de Jesus GR, et al. The association between antiphospholipid antibodies and pregnancy morbidity, stroke, myocardial infarction, and deep vein thrombosis: A critical review of the literature. Lupus. 2015;24(9):980-984.

3. Andreoli L, Chighizola CB, Banzato A, Pons-Estel GJ, Ramire de Jesus G, Erkan D. Estimated frequency of antiphospholipid antibodies in patients with pregnancy morbidity, stroke, myocardial infarction, and deep vein thrombosis: A critical review of the literature. Arthritis Care Res (Hoboken). 2013;65:1869-1873.

4. Ruis-Irastorza G, Crowther M, Branch W, Khamashta MA. Antiphospholipid syndrome. Lancet. 2010;376:1498-1509.

5. Arachchillage DJ, Cohen H. Use of new oral anticoagulants in antiphospholipid syndrome. Curr Rheumatol Rep. 2013;15:331-340.

6. Miyakis S, Lockshin MD, Atsumi T, et al. International consensus statement on an update of the classification criteria for definite antiphospholipid syndrome (APS). J Thromb Haemost. 2006;4(2):295-306.

7. Muscal E, Brey RL. Neurological manifestations of the antiphospholipid syndrome: Risk assessment and evidence based medicine. Int J Clin Pract. 2007;61:1561-1568.

8. Levine J, Branch D, Rauch J. The antiphospholipid syndrome. N Engl J Med. 2002;346:752-763.

9. Olson JD, Eby C. Arterial and venous thrombosis in adults. In: Kottke-Marchant K, ed. An Algorithmic Approach to Hemostasis Testing. 1st ed. Northfield, IL: College of American Pathologists; 2008:239-266.

10. Pengo V, Tripodi A, Reber G, et al. Update of the guidelines for lupus anticoagulant detection. J Thromb Haemost. 2009;7:1737-1740.
11. Kearon C, Akl EA, Ornelas J et al. Antithrombotic therapy for VTE disease CHEST guideline and Expert Panel Report. CHEST. 2016;149(2):315-352.

12. Kearon C, Akl EA, Comerota AJ, et al. Antithrombotic therapy for VTE disease. Antithrombotic therapy and prevention of thrombosis. 9th ed. American College of Chest Physicians Evidence-Based Clinical Practice Guidelines. CHEST. 2012;141(2)(suppl):e419S-e494S.

13. Crowther MA, Ginsberg JS, Julian J, et al. A comparison of two intensities of warfarin for the prevention of recurrent thrombosis in patients with the antiphospholipid antibody syndrome. N Engl J Med. 2003;349:1133-1138.

14. Finazzi G, Marchioli R, Brancaccio V, et al. A randomized clinical trial of high-intensity warfarin vs. conventional antithrombotic therapy for the prevention of recurrent thrombosis in patients with the antiphospholipid syndrome (WAPS). J Thromb Haemost. 2005;3:848-853.

15. Cohen H, Machin SJ. Antithrombotic treatment failures in antiphospholipid syndrome: The new anticoagulants? Lupus. 2010:19:486-491.

16. Erkan D, Aguiar CL, Andrade D, et al. 14th International Congress on Antiphospholipid Antibodies Task Force Report on Antiphospholipid Syndrome treatment trends. Autoimmun Rev. 2014;13:685-696.

17. Rivaroxaban [package insert]. Titusville, NJ: Janssen Pharmaceuticals, Inc.; 2011.

18. Apixaban [package insert]. Princeton, NJ: Bristol-Myers Squibb Company; 2012.

19. Edoxaban [package insert]. Parsippany, NJ: Daiichi Sankyo, Inc; 2015.

20. Chan NC, Bhagirath V, Eikelboom JW. Profile of betrixaban and its potential in the prevention and treatment of venous thromboembolism. Vasc Health Risk Manage. 2015:11;343-351.

21. Dabigatran [package insert]. Ridgefield, CT: Boehringer Ingelheim Pharmaceuticals, Inc.; 2015.

22. January CT, Wann LS, Alpert JS, et al. 2014 AHA/ACC/ HRS guideline for the management of patients with atrial fibrillation: A report of the American College of Cardiology/ American Heart Association Task Force on Practice Guidelines and the Heart Rhythm Society. J Am Coll Cardiol. 2014;64:e1-76.

23. Signorelli F, Nogueira F, Domingues V, Mariz HA, Levy RA. Thrombotic events in patients with antiphospholipid syndrome treated with rivaroxaban: A series of eight cases. Clin Rheumatol. 2015. http://ink.springer.com/ article/10.1007\%2Fs10067-015-3030-y. Accessed November 23, 2015 .

24. Win K, Rodgers GM. New oral anticoagulants may not be effective to prevent venous thromboembolism in patients with antiphospholipid syndrome. Am J Hematol. 2014;89:1017. 
25. Schaefer JK, McBane RD, Black DF, Williams LN, Moder KG, Wysokinski WE. Failure of dabigatran and rivaroxaban to prevent thromboembolism in antiphospholipid syndrome: A case series of three patients. Thromb Haemost. 2014;112: 947-950.

26. Son M, Wypasek E, Celinska-Lowenhoff M, Undas A. The use of rivaroxaban in patients with antiphospholipid syndrome: A series of 12 cases. Thromb Res. 2015;135:1035-1036.

27. Savino S, Breen K, Hunt BJ. Rivaroxaban use in patients with antiphospholipid syndrome and previous venous thromboembolism. Blood Coagul Fibrinolysis. 2015;26:476-478.

28. Noel N, Dutasta F, Costedoat-Chalumeau N, et al. Safety and efficacy of oral direct inhibitors of thrombin and factor $\mathrm{Xa}$ in antiphospholipid syndrome. Autoimmun Rev. 2015;14:680-685.

29. Cohen H, Dore CJ, Clawson S, et al. Rivaroxaban in antiphospholipid syndrome (RAPS) protocol: A prospective, randomized controlled phase II/III clinical trial of rivaroxaban versus warfarin in patients with thrombotic antiphospholipid syndrome, with or without SLE. Lupus. 2015;24:1087-1094.

30. Pengo V, Banzato A, Bison E, et al. Efficacy and safety of rivaroxaban vs warfarin in high-risk patients with antiphospholipid syndrome: Rationale and design of the Trial on Rivaroxaban in AntiPhospholipid Syndrome (TRAPS) trial. Lupus. 2015;0:1-6.

31. Woller SC, Stevens SM, Kaplan DA, et.al. Apixaban for the Secondary Prevention of Thrombosis Among Patients With Antiphospholipid Syndrome. Clinical and Applied Thrombosis/ Hemostasis (ASTRO-APS). Clin Appl Thromb Hemost. 2015:1-9.
32. Schulman S, Kearon C, Kakkar AJ, et al. Dabigatran versus warfarin in the treatment of acute venous thromboembolism. N Engl J Med. 2009;361(24):2341-2352.

33. Büller HR. Once-daily oral rivaroxaban versus placebo in the long-term prevention of recurrent symptomatic venous thromboembolism, the Einstein-Extension Study. Late Breaking Abstracts LBA-2. 51st ASH Annual Meeting and Exposition; 2009.

34. EINSTEIN Investigators, Bauersachs R, Berkowitz SD, Brenner B, Buller HR, Decousus H, et al. Oral rivaroxaban for symptomatic venous thromboembolism (and supplementary appendix). N Engl J Med. 2010;363:2499-2510.

35. EINSTEIN-PE Investigators, Büller HR, Prins $\mathrm{MH}$, Lensin AW, et al. Oral rivaroxaban for the treatment of symptomatic pulmonary embolism. $N$ Engl J Med. 2012;366: 1287-1297.

36. Martinuzzo ME, Barrera LH, D'adamoMA, Otaso JC, Gimenez MI, Oyhamburu J. Frequent false-positive results of lupus anticoagulant tests in plasmas of patients receiving the new oral anticoagulants and enoxaparin [published online ahead of print September 6, 2013]. Int J Lab Hematol, http:// dx.doi.org/10.1111/ijlh.12138.

37. Eby C. Novel anticoagulants and laboratory testing. Int J Lab Hematol. 2013;35:262-268.

38. Nakashima MO, Rogers HJ. Hypercoagulable states: An algorithmic approach to laboratory testing and update on monitoring of direct oral anticoagulants. Blood Res. 2014;49(2):85-94.

39. Fawole A, Daw HA, Crowther MA. Practical management of bleeding due to the anticoagulants dabigatran, rivaroxaban, and apixaban. Cleve Clin J Med. 2013;80(7):443-451. 